\title{
HIPM Is a Susceptibility Gene of Malus spp.: Reduced Expression Reduces Susceptibility to Erwinia amylovora
}

\author{
Manuela Campa, ${ }^{1}$ Stefano Piazza, ${ }^{1}$ Laura Righetti, ${ }^{1}$ Chang-Sik Oh, ${ }^{2}$ Lorenza Conterno, ${ }^{1}$ \\ Ewa Borejsza-Wysocka, ${ }^{3}$ Kanchiswamy Chidananda Nagamangala, ${ }^{1}$ Steven Vincent Beer, ${ }^{4}$ \\ Herbert Sanders Aldwinckle, ${ }^{3}$ and Mickael Malnoy ${ }^{1, \dagger}$ \\ ${ }^{1}$ Research and Innovation Centre, Fondazione Edmund Mach (FEM), Via Mach 1, 38010 San Michele all'Adige (TN), Italy; \\ ${ }^{2}$ Department of Horticultural Biotechnology, Kyung Hee University, Yongin 17104, South Korea; ${ }^{3}$ Section of Plant Pathology and \\ Plant-Microbe Biology, School of Integrative Plant Sciences, Cornell University, Geneva, NY 14456, U.S.A.; and ${ }^{4}$ Plant \\ Sciences, Cornell University, Ithaca, NY 14853, U.S.A.
}

Accepted 9 July 2018.

\begin{abstract}
Fire blight, a devastating disease caused by the bacterium Erwinia amylovora, is a major threat to apple crop production. To improve our understanding of the fire blight disease and to identify potential strategies to control the pathogen, we studied the apple protein HIPM (for HrpN-interacting protein from Malus spp.), which has previously been identified as interacting with the $E$. amylovora effector protein HrpN. Transgenic apple plants were generated with reduced $H I P M$ expression, using an RNA interference construct, and were subsequently analyzed for susceptibility to $E$. amylovora infection. Lines exhibiting a greater than $50 \%$ silencing of $H I P M$ expression showed a significant decrease in susceptibility to $E$. amylovora infection. Indeed, a correlation between HIPM expression and $E$. amylovora infection was identified, demonstrating the crucial role of HIPM during fire blight disease progression. Furthermore, an apple oxygen-evolving enhancer-like protein (MdOEE) was identified via a yeast two-hybrid screen to interact with HIPM. This result was confirmed with bimolecular fluorescence complementation assays and leads to new hypotheses concerning the response mechanism of the plant to $E$. amylovora as well as the mechanism of infection of the bacterium. These results suggest that MdOEE and, particularly, HIPM are promising targets for further investigations toward the genetic improvement of apple.
\end{abstract}

Apple (Malus $\times$ domestica) is one of the most important cultivated fruit species for human consumption. Like other crops, apple is threatened by a wide range of bacterial, fungal, oomycete, and viral pathogens. One of the most devastating pathogens for apple is Erwinia amylovora (Burrill) (Winslow et al. 1920), the member of the family Enterobacteriaceae

Current address for Manuela Campa: Department of Genetics, Stellenbosch University, Matieland, 7602, South Africa

${ }^{\dagger}$ Corresponding author: Mickael Malnoy;

E-mail: mickael.malnoy@fmach.it or mcampa@sun.ac.za

Funding: This work was funded by the autonomous Province of Trento (Italy).

*The $\boldsymbol{e}$-Xtra logo stands for "electronic extra" and indicates that nine supplementary figures and one supplementary table are published online.

(C) 2019 The American Phytopathological Society responsible for fire blight disease, which is widespread in several countries (Gusberti et al. 2015; Malnoy et al. 2012). Control of this disease is difficult and is typically achieved through eradication of entire trees displaying symptoms or through preventive spraying of copper or antibiotics. However, these strategies are not completely effective when used in isolation (Malnoy et al. 2012), and the use of antibiotics generally has been discouraged because of the evolution of resistance in pathogen populations and the potential transfer of antibiotic resistance to pathogens of clinical importance (Sundin et al. 2016).

Genetic resistance has been shown to play an important role in the management of fire blight. Both classical breeding and new breeding technologies, aimed at the creation of resistant cultivars, have targeted bacterial disease management (Aldwinckle et al. 1976; Broggini et al. 2014; Calenge et al. 2005; Durel et al. 2009; Emeriewen et al. 2014, 2015; Gardiner et al. 2012; Khan et al. 2006; Kost et al. 2015; Le Roux et al. 2010; Peil et al. 2007; Perazzolli et al. 2014). These processes are time-consuming and, in the case of classical breeding, the quality of the new cultivar often is inferior to that of commercially available apples, hindering consumer acceptance. In the case of new breeding technologies, the resistance conveyed by a resistance gene can be overcome by the pathogen over a period of time (Vogt et al. 2013). To develop novel forms of disease control, understanding the key determinants of the relevant plant-pathogenic bacterium-host interaction is crucial (Sundin et al. 2016).

Infection of apple by E. amylovora results in browning and necrosis of the infected parts in the susceptible host plants. A typical hypersensitive reaction (HR) (rapid and localized plant cell death at the infection site) develops in nonhost plants (Lee et al. 2017). Interestingly, E. amylovora infection of host plants results in the production of reactive oxygen species (ROS), as shown in pear by Venisse et al. (2001). This is important as ROS production is typically seen as a HR response in the incompatible or nonhost plants. However, in the case of E. amylovora, ROS production is, in fact, necessary for the bacteria to succeed in pathogenesis (Venisse et al. 2001, 2002, 2003). As it has been found in other necrogenic bacteria, E. amylovora possesses hrp genes, which are involved in the elicitation of the HR in nonhost plants, in pathogenesis in compatible host plants, or both (Venisse et al. 2003). Some of these genes encode proteins of the type III secretion system (T3SS), the apparatus used to export and deliver effector proteins into the cytosol of host plant cells (Vrancken et al. 2013). Twelve proteins, including Eop1, Eop3, Eop4, DspA/E, Eop2, 
HrpK, HrpN, HrpW, and HrpJ, have been found to be secreted by E. amylovora (Nissinen et al. 2007). HrpN is of particular interest, as it has been identified as a primary determinant of pathogenicity in E. amylovora (Wei et al. 1992) and the major HR elicitor (Venisse et al. 2003). $\mathrm{DspA} / \mathrm{E}$ is also required for pathogenicity in apple and pear (Bogdanove et al. 1998; Gaudriault et al. 1997) and is one of the best-studied effectors (Holtappels et al. 2016). Both Bocsanczy et al. (2008) and Venisse et al. (2003) described a strong interaction between $\operatorname{HrpN}$ and DspA/E; HrpN appears to facilitate the translocation of DspA/E into plant cells, while both HrpN and DspA/E are necessary for the production of the ROS required by the bacteria for infection.

The centrality of the secretion system and the effector proteins that it delivers to the host cells represent attractive targets for further investigation and potential manipulation with novel disease management strategies in mind. Most effector proteins appear to act inside the host cell and some have been shown to interact with factors encoded by the host genome. These host genes are of primary interest, as they may represent susceptibility $(S)$ genes, i.e., plant genes that facilitate the compatible interaction between plants and pathogens and, therefore, the progression of the disease (van Schie and Takken 2014). The same authors predicted that $S$ gene-based resistance generally would be more durable than resistance $(R)$ gene-based resistance, primarily because there is no potential $R$ gene to overcome. Mutation or loss of an $S$ gene thus has the potential to limit the ability of the pathogen to cause disease.

Previous studies with $\mathrm{HrpN}$ identified an apple protein via a yeast two-hybrid analysis that interacts with $\mathrm{HrpN}$ and termed HIPM (for HrpN-interacting protein of Malus spp.) (Oh and Beer 2007). HIPM is a transmembrane protein of 60 amino acids that was shown to be expressed constitutively in apple tissues. Stronger expression of HIPM was observed in flowers (an important site of infection for E. amylovora) than in leaves and shoots (Oh and Beer 2007). In Arabidopsis thaliana, the HIPM ortholog functions as a negative regulator of plant growth (Oh and Beer 2007); however, its role in its native plant, apple, needs to be fully characterized. HIPM is hypothesized as an essential transmembrane receptor for the important E. amylovora effector HrpN, which is necessary for infection. Therefore, HIPM might be considered encoded by an ' $S$ gene', in current terminology (van Schie and Takken 2014). In this paper, silencing of HIPM is demonstrated in transgenic apple (cv. Galaxy), which resulted in significantly reduced susceptibility of apple to E. amylovora. Furthermore, we identify an oxygen-evolving enhancer-like protein (OEE) from apple (MdOEE) that interacts with HIPM. This opens new hypotheses and gives new inputs in the understanding of the plant response mechanism to E. amylovora and the progression of the fire blight disease.

\section{RESULTS}

\section{HIPM occurs across Magnoliophyta genomes.}

HIPM (EU078328) was identified by Oh and Beer (2007) via screening a yeast two-hybrid library with the Erwinia amylovora effector HrpN. The HIPM gene encodes a protein of approximately $6.5 \mathrm{kDa}$, which contains 60 amino acids (aa) (Supplementary Fig. S1). In reality, two copies of this gene (MDP0000657507 and MDP0000368495) are present in the Malus $\times$ domestica genome (cv. Golden Delicious) in duplicated chromosomes (LG 3 and LG 11). Both genes code for proteins composed of 60 aa sharing a $100 \%$ aa identity and a $97 \%$ nucleotide identity. Due to this extreme sequence conservation, the two genes were treated as one with regards to

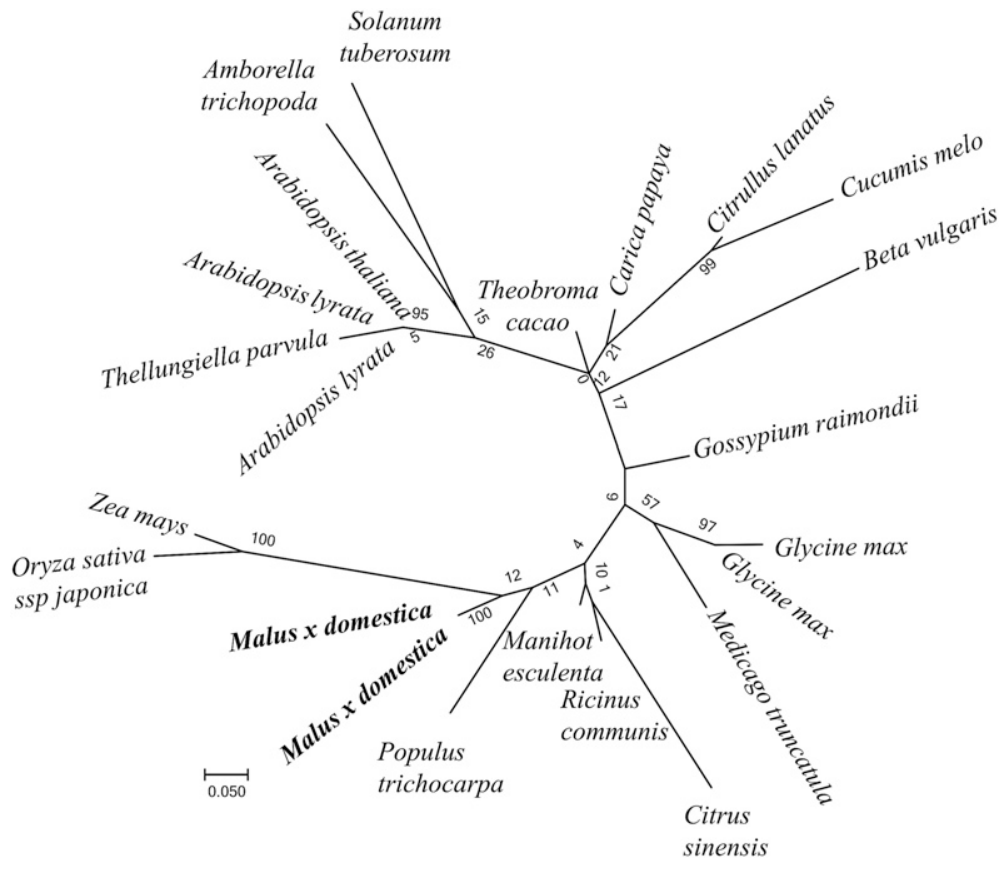

Fig. 1. Molecular phylogenetic analysis of HIPM (HrpN-interacting protein from Malus) orthologs. Alignments were performed using the ClustalW algorithm. MEGA7 software was used to compute the maximum likelihood tree with significance percentages (bootstrap values out of 1,000). Bar represents the relative amino acid difference. Plant species (apple underlined) in the image relate to the following protein ID numbers: Arabidopsis lyrata (AL0G09750, AL3G16330), Arabidopsis thaliana (AT3G15395), Amborella trichopoda (ATR_00061G00150), Beta vulgaris (BV3G02720), Citrullus lanatus (CL07G06470), Cucumis melo (CM00028G01130), Carica papaya (CP00080G00440), Citrus sinensis (CS00012G00140), Glycine max (GM12G23171, GM06G38130), Gossypium raimondii (GR02G07240), Malus $\times$ domestica (MDP000036849, MDP000065750), Manihot esculenta (ME05144G00060), Medicago truncatula (MT8G043400), Oryza sativa ssp japonica (OS02G10370), Populus trichocarpa (PT01G40200), Ricinus communis (RC29953G00070), Solanum tuberosum (ST02G025880), Theobroma cacao (TC0007G07500), Thellungiella parvula (TP3G13650), and Zea mays (ZM05G23370). 

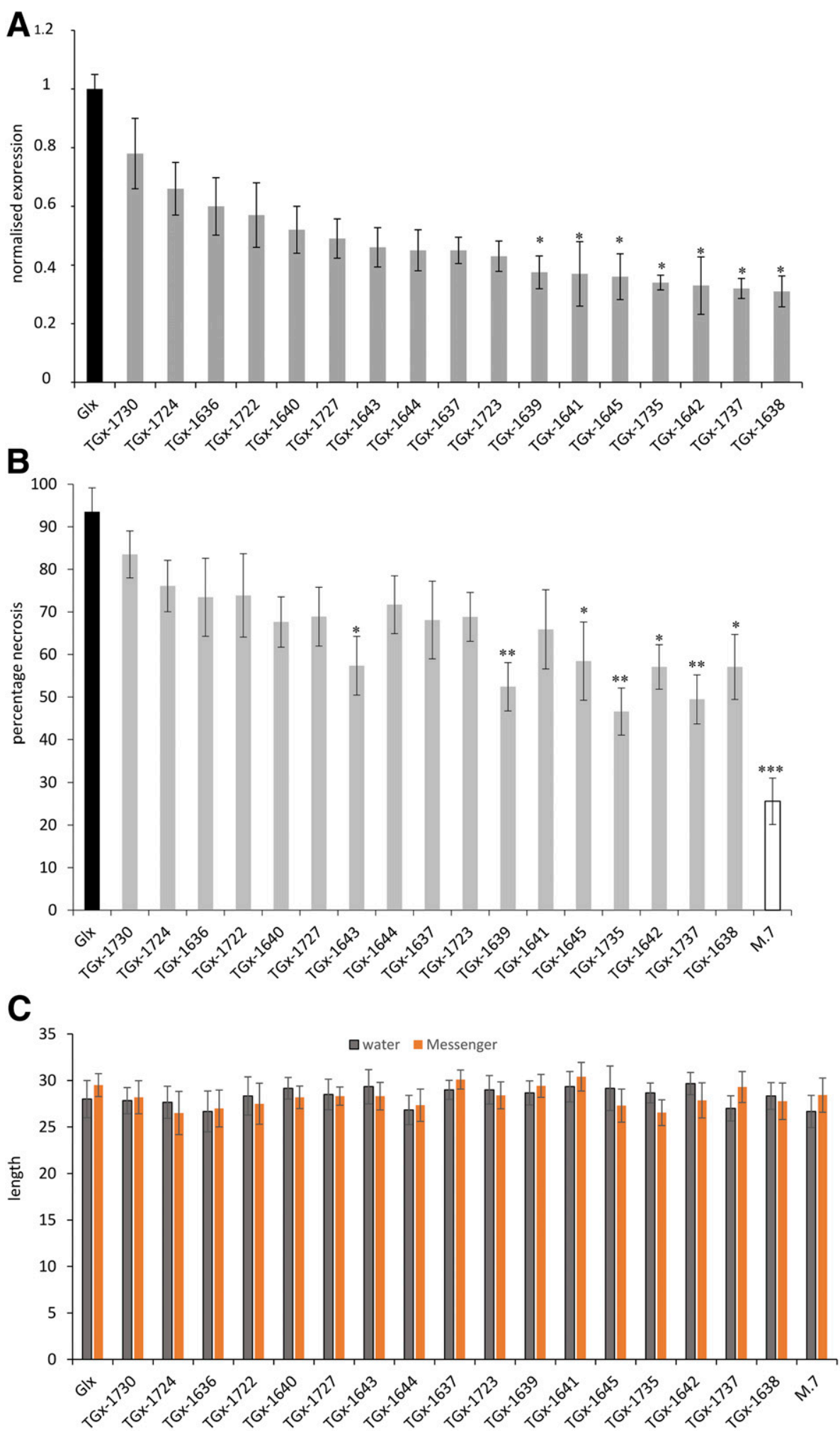

Fig. 2. Molecular and phenotypical analysis of 17 transgenic apple lines. A, Relative expression of HIPM gene in transgenic lines of apple plants compared with control plants (apple cv. Galaxy [Glx], set as 1). Level of HIPM expression ranged from 30 to $70 \%$ relative to Glx in different transgenic lines. Results are shown with standard error bars $(n=5)$. Asterisks indicate significant difference compared with Glx, according to the Tukey's test $(P<0.05)$. B, Percentage of necrosis (shown with 95\% confidence interval bar). Susceptibility of transgenic apple lines to Erwinia amylovora in comparison with wild-type M.7 apple rootstock (resistant to fire blight) and Glx (susceptible to fire blight). Lengths of shoot and the portions that appeared necrotic were measured 1 month after inoculation with E. amylovora. Transgenic clone susceptibility is significantly different from Glx at $P<0.05$ (one asterisk [*]), $P<0.01$ (two asterisks [**]), and $P<0.001$ (three asterisks [***], according to Kruskall and Wallis test. C, Growth of controls (Glx and M.7) and transgenic plants under normal conditions and 1 week after treatment with Messenger $(n=6)$. 
silencing and gene expression quantification. Orthologs of HIPM (gene family ORTHO03D011477) were found in 20 different plant genomes of the 31 present in the PLAZA 3.0 database. The phylogenetic analysis (Fig. 1) shows how conserved the protein is throughout the different species (14 aa, mainly at the $\mathrm{C}$-terminal of the protein, are conserved in all the plant species). The apple and poplar (PT01G40200) proteins are closely related (73\% aa identity), while apple and Arabidopsis (AT3G15395) are relatively distant (63\% aa identity).

\section{Silencing of HIPM in apple reduces the plant susceptibility to Erwinia amylovora infection.}

A total of 17 RNA interference (RNAi) transgenic lines were obtained in three independent transformation experiments (5.6\% transformation efficiency). The RNAi lines were confirmed for the presence of the NPTII gene and the 35S-HIPM construct (Supplementary Fig. S2). Silencing of HIPM was evaluated in plants growing in the glasshouse; two leaves were collected from each plant (at least five replicates for each transgenic line). Quantitative reverse transcription-polymerase chain reaction (qRT-PCR) analysis revealed expression between 30 and $70 \%$ less than that in the wild-type plants (Fig. 2A).

To characterize the response of the transformed lines to fire blight, 10 to 20 acclimated plants per line were inoculated with E. amylovora Ea273 at $5 \times 10^{7} \mathrm{CFU} \mathrm{ml}^{-1}$. The nontransformed apple (control) was susceptible, showing an average necrosis of $93 \%$, while several transgenic lines showed significantly lower necrosis (Fig. 2B). In fact, as much as a $50 \%$ reduction in necrosis was observed in some transgenic lines when inoculated with strain Ea273. The relatively small confidence intervals indicate the consistency in the observed responses. We also observed that, 3 weeks after inoculation, the symptoms in the transgenic lines ceased (after the small progression in the plant as shown in Figure 3A) and, subsequently, new shoots without symptoms develop. In contrast, in wild-type lines the symptoms continue to progress until the plants die (Supplementary Fig. S3).

Oh and Beer (2007) observed an increase in the aerial growth and a lack of response to HrpN protein (Messenger) in Arabidopsis knock-out mutants. However, in apple, the silencing of HIPM in the cv. Galaxy did not affect the growth of the plant. We observed no difference in growth between nontransformed and transformed plants grown for one year in glasshouse conditions regardless of HIPM silencing (Supplementary Fig. S4). Furthermore, plants treated with the HrpN protein (Messenger) did not differ in plant growth over one week relative to nontreated plants (Fig. 2C).

Three of these transgenic lines (TGx-1735, TGx-1638, and TGx-1639) were selected based on their level of gene silencing and susceptibility to fire blight and were propagated in vitro. After 5 years of micropropagation, they were acclimated in
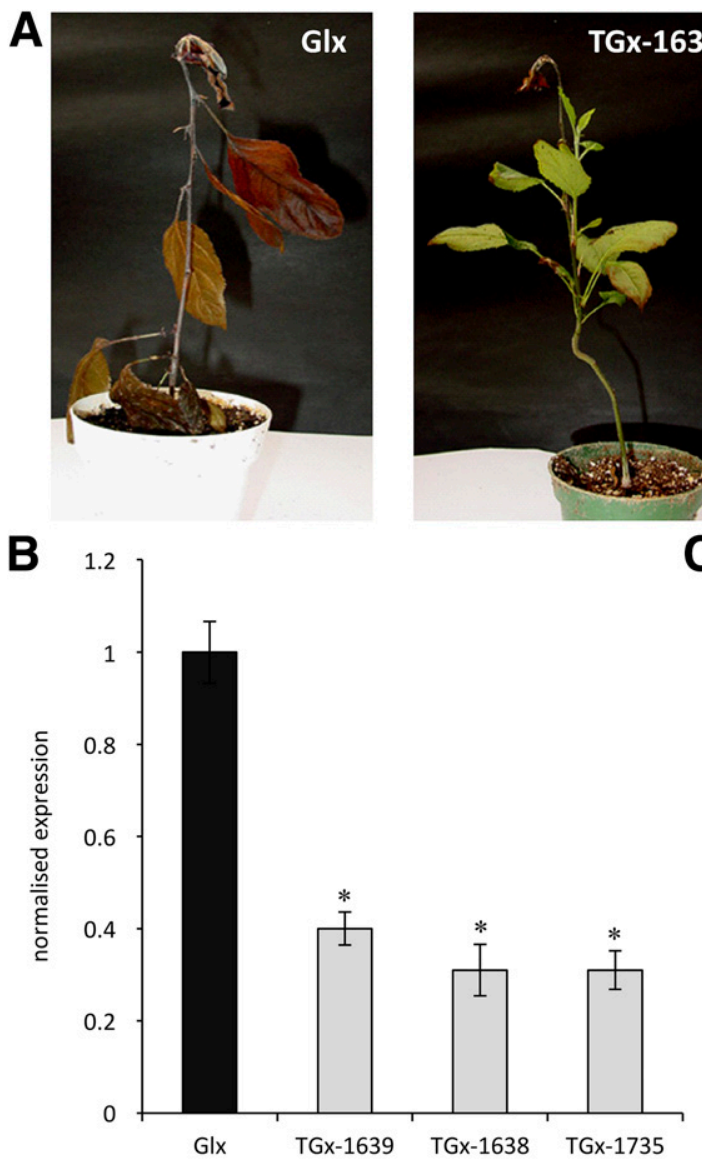
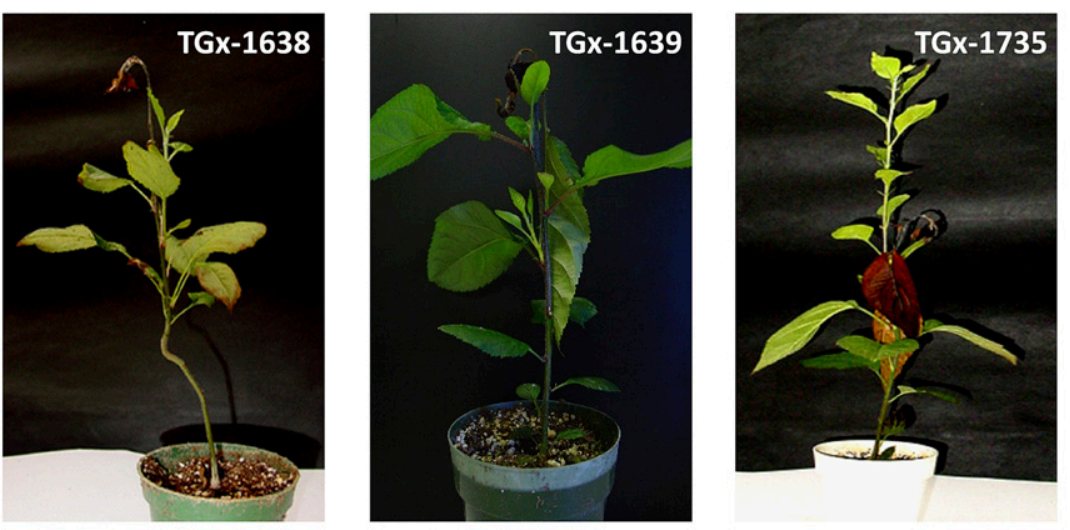

C

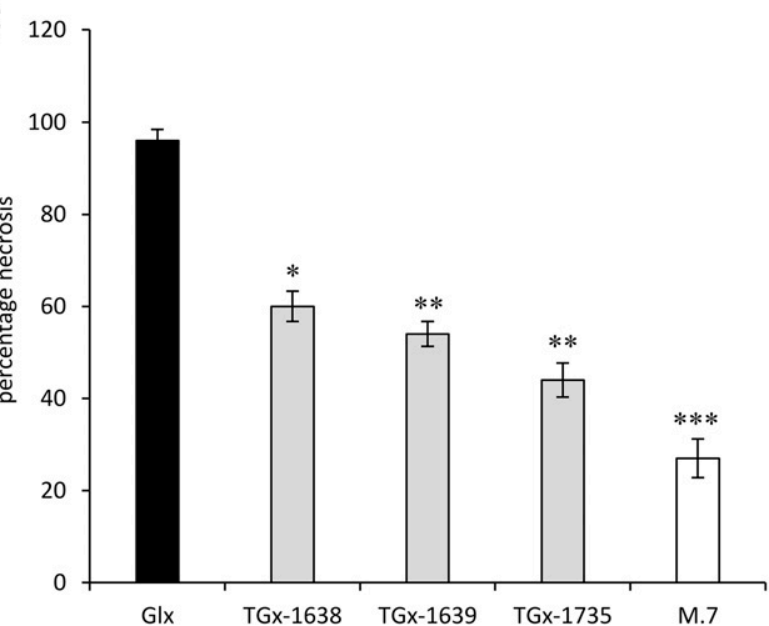

Fig. 3. Reduced HIPM expression and susceptibility to Erwinia amylovora confirmed after 5 years of micropropagation of selected transgenic lines (TGx-1638, TGx-1639, TGx-1735). A, Pictures of the typical response of apple cv. Galaxy (Glx) and transgenic lines after inoculation with E. amylovora. B, Expression of $H I P M$ in the three transgenic lines and Glx was assessed again 5 years after propagation. Gene expression variance was analyzed by one-way analysis of variance, followed by posthoc Tukey's test. Asterisks indicate significant reduction $(P<0.05)$ compared with control plants $($ Glx set as 1$)$. Results are shown with standard error bar of the means $(n=3)$. C, Percentage of necrosis (shown with $95 \%$ confidence interval bar), measured as the length of shoot and the portions that appeared necrotic 1 month after inoculation with $E$. amylovora. Transgenic clone susceptibility is significantly different from Glx at $P<0.05$ (one asterisk [*]), $P<0.01$ (two asterisks [**]), and $P<0.001$ (three asterisks [***]), according to Kruskall and Wallis test. 
the glasshouse, and their HIPM expression and responses to inoculation with $E$. amylovora Ea273 were assessed de novo (Fig. 3). The level of silencing and the significant decrease of susceptibility observed previously were maintained, confirming stability of resistance in these transgenic lines. Of these three lines, HIPM expression was assessed also after infection with $E$. amylovora and it was found that the expression in transgenic lines was unaffected by E. amylovora infection and was significantly lower when compared with the control lines (Supplementary Fig. S5).

\section{The apple OEE protein interacts with HIPM.}

To identify HIPM-interacting proteins, a yeast two-hybrid assay with the full-length HIPM as bait was used for screening a cDNA library of 'Golden Delicious' apple. From the $1.25 \times$ $10^{7}$ clones screened, nine positive clones were initially identified, and, after a more stringent selection, only four of them remained positive. These four clones, after sequencing, corresponded to the apple sequence MDP0000248920 (Supplementary Fig. S6, for alignment). The protein encoded presents an amino acid homology to OEE1 and is therefore named MdOEE.

To confirm the interaction between HIPM and MdOEE in planta, a bimolecular fluorescence complementation (BiFC) assay in Nicotiana benthamiana leaves was performed. Sequence of $M d O E E$ and $H I P M$ were amplified from apple cDNA and were cloned in different BiFC vectors. The cells cotransformed with the AtImpa-4/VirE2 positive interaction (Lee et al. 2008) produced a strong fluorescence signal that was localized in the nucleus (Fig. 4). However, in N. benthamiana leaves, a strong yellow fluorescence was produced when Nterminus HIPMfusedNhalfYFP and NterminusOEE-fusedChalfYFP (nYFP-HIPM/ cYFP-OEE) were cotransformed. In contrast, no fluorescent signal was observed when nYFP-HIPM/OEE-cYFP or $N A D P H$-NYFP (used a negative control) were coexpressed in $N$. benthamiana leaves. This confirmed our yeast two-hybrid results showing that HIPM protein specifically interacts with OEE. Yellow fluorescent protein (YFP) localization assays demonstrated that MdOEE localizes on the plasma membrane and in the nucleus (together with HIPM) (Supplementary Fig. S7), while a transmembrane domain is predicted by the Expasy PredictProtein software.

\section{Gene expression in response}

to Erwinia amylovora infection.

To understand how MdOEE is involved in the response of apple to E. amylovora infection, expression of this gene was analyzed by qRT-PCR in the wild type and the selected transgenic lines before and after inoculation. The MdOEE expression analysis did not show any significant changes (Supplementary Fig. S8), indeed only in the TGx-1735 line was $M d O E E$ expression significantly lower after infection than in the control plants.

Expression of relevant genes (Baldo et al. 2010; Sarowar et al. 2011; Venisse et al. 2002; Vergne et al. 2014) was analyzed by qRT-PCR, i.e., chalcone synthase, glutathione transferase, enhanced disease susceptibility 1 , and lipoxygenase $(L O X)$. The only significant expression difference between wild-type and transgenic plants was observed for $L O X$, in particular, it is down-regulated by E. amylovora infection in transgenic plants (TGx-1638 and TGx-1735) while, in wild type, the expression does not change after E. amylovora infection. (Supplementary Fig. S9).

\section{DISCUSSION}

Improvement of woody fruit crops, such as apple, via classical breeding is not an efficient process, due, in part, to the high heterozygosity of the genome and the long reproductive cycle of the plant. Genetic engineering can offer an alternative to address the disease problems farmers face. In the case of

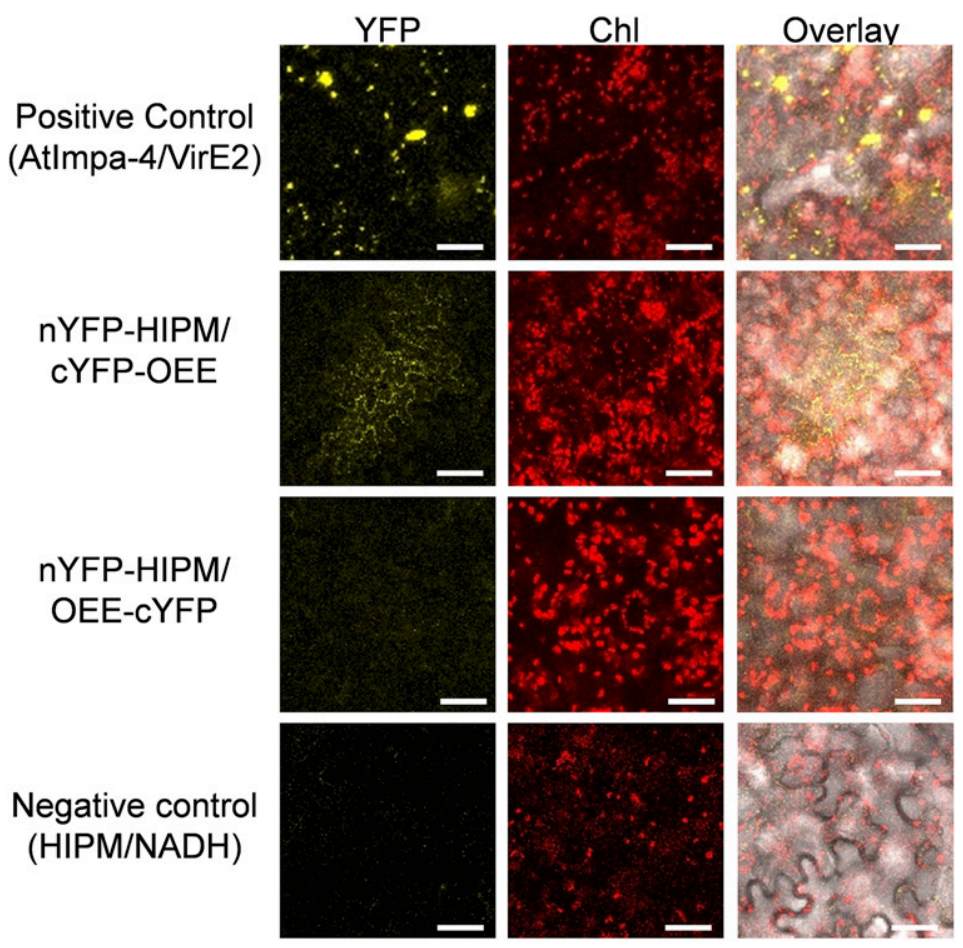

Fig. 4. Bimolecular fluorescence complementation (BiFC) assays for testing protein interaction in leaves of Nicotiana benthamiana. Interactions between AtImpa-4-Vir2 and HIPM-NADPH were included, respectively, as positive (top lane) and negative (bottom lane) controls. In the second lane from the top, the positive interaction between HIPM and MdOEE with yellow fluorescent protein (YFP) at the N-terminal of both proteins (nYFP-HIPM and cYFP-OEE) is shown. In the third lane from the top, the negative interaction between HIPM with YFP at the N-terminal (nYFP-HIPM) and MdOEE with YFP at the C-terminal (OEE-cYFP) is shown. The scale bars represent $50 \mu \mathrm{m}$. 
E. amylovora, $\mathrm{HrpN}$, one of the chief virulence factors of E. amylovora (Wei et al. 1992), interacts with the small transmembrane apple protein HIPM (Oh and Beer 2007). Thus, HIPM, the apple protein that facilitates the successful interaction between apple and E. amylovora, can be considered an important and appropriate target in the quest for control of fire blight. To test this hypothesis, transgenic apple lines were produced with reduced expression of HIPM. Plants with reduced expression of HIPM also were reduced in susceptibility to E. amylovora. This highlights the importance of HIPM during infection by E. amylovora. From a practical standpoint, this is a major step forward, since new breeding strategies directed toward knocking out the HIPM gene, perhaps via genome editing techniques like CRISPR/Cas9, could provide a durable solution to fire blight. From the fundamental standpoint, silencing HIPM, an $S$ gene (a gene essential for proper plant-pathogen compatibility), is likely to be more durable than incorporating $R$ genes, which already have been overcome by the pathogen, as documented in cases of the MdRin4 and FB_MR5 fire blight resistance genes of apple (Kost et al. 2015; Vogt et al. 2013).

HIPM orthologs had been characterized in rice and Arabidopsis (Oh and Beer 2007). With the recent increase in the number of plant genome sequences available, it is now possible to identify HIPM orthologs in more plant species. Indeed, we found HIPM orthologs in 20 different plant species (of 31 analyzed) for which genome information is available and, in all of them, at least 14 of the 60 aa were conserved. The fact that this protein can be found in many plant species belonging to different classes (monocots, dicots, woody, and herbaceous) demonstrates that HIPM is conserved throughout the plant kingdom, as suggested earlier by Oh and Beer (2007). Interestingly, HIPM may have diverse functions in different plants, as shown by the fact that, in Arabidopsis, AtHIPM knockout mutants show an increase in aerial plant growth, suggesting that HIPM acts as a negative regulator of plant growth (Oh and Beer 2007). In the present work, silencing of HIPM in apple showed no effect on plant growth, suggesting it is not involved in growth regulation. The relative phylogenetic divergence observed between Arabidopsis and apple HIPM proteins may explain this difference in physiological roles. Furthermore, the Oh and Beer (2007) study considered a gene knockout while, in this study, we are assessing plants with reduced (but not knocked out) gene expression (Fig. 1A), potentially explaining the difference in phenotype. A reduction of HIPM expression in apple significantly increased the plant resistance to fire blight when compared with wild-type plants. The increased levels of resistance (decrease in susceptibility) observed in the different transgenic lines can be correlated with the reduction of HIPM expression. In three of the 17 lines tested, the level of susceptibility was decreased by almost $50 \%$ as compared with the wild type (Fig. 2). These results highlight the important role for HIPM in the propagation of the symptoms of fire blight disease. This can be partially explained by the fact that the effector HrpN has less 'opportunity' of binding with the target protein (HIPM) and this lack of interaction results in a decrease in the progression of infection.

The role of $\mathrm{HrpN}$ in the infection of E. amylovora in apple is not yet known but may involve the creation of a pore, which facilitates the translocation of other effectors of E. amylovora (such as DspE/A) (Bocsanczy et al. 2008). The function of the $H I P M$ gene may be compared with the function of the $S$ gene $M L O$ (mildew resistance locus $\mathrm{O}$ ), which is necessary for infection by powdery mildew (Pessina et al. 2016). In Arabidopsis, AtMLO2 was found to interact with the Pseudomonas effector HopZ2 and to act like a negative regulator of immunity (Lewis et al. 2012). In general, we can assume that HIPM, as an
$S$ gene, contributes to the infection in the first phase facilitating host recognition and penetration. HIPM can also be important in providing the necessary tools for the bacterial infection, as in rice SWEET proteins, which interact with Xanthomonas effectors and provide sugars for the pathogen (van Schie and Takken 2014).

To discover other 'actors' in the apple-E. amylovora pathogenic system, screening of a yeast two-hybrid library was performed with HIPM as bait. Only one protein was found to interact with HIPM, the oxygen-evolving enhancer protein MdOEE. MdOEE shows a conserved sequence in the Viridiplantae family, with 54 homologous genes in 31 species. In spinach, this protein has been described as having an essential role in the protection of photosystem II (PSII), possibly assisting in the production of ROS (Yamamoto et al. 1998), which, in general, is the accepted primary function of PSII. There are a number of reports suggesting OEE plays a role in response to pathogens, in $N$. benthamiana in response to Tobacco mosaic virus (Abbink et al. 2002), in soybean in response to Pseudomonas spp. (Zou et al. 2005), in Arabidopsis inoculated with Pseudomonas spp. (Jones et al. 2006), and in citrus infected with 'Candidatus Liberibacter asiaticus' (Nwugo et al. 2013). In apple, the function of OEE is not yet described, but it has already been shown that, after infection of apple with E. amylovora, genes of the photosynthesis pathway are affected (Baldo et al. 2010; Kamber et al. 2016; Sarowar et al. 2011). Further, it is interesting to note that the other important E. amylovora effector (DspA/E) interacts with a preferredoxin, which is an electron carrier in PSI (Holtappels et al. 2016). It therefore seems that multiple photosynthesis proteins are involved in the response to E. amylovora infection.

MdOEE may be involved in the response to the pathogen infection in many different ways, including, singly or in combination, ROS production, membrane stabilization, and interaction with other proteins necessary for infection. MdOEE expression analysis is not very explicative since only one transgenic line shows significant expression reduction compared with the wild-type plants. The importance of ROS and oxidative burst for successful infection by E. amylovora has been demonstrated in pear and apple (Venisse et al. 2001, 2002, 2003). Venisse et al. (2003) demonstrated the role of HrpN and $\mathrm{DspA} / \mathrm{E}$ in the induction of the oxidative burst of $E$. amylovora in host plants during compatible interaction. As HIPM interacts with both HrpN and MdOEE, this may represent a possible route through which the production of ROS is stimulated. Additional experiments aimed at the elucidation of the role of OEE during infection may provide some insight into this speculation.

In conclusion, apple plants with a reduced susceptibility to E. amylovora infection have been produced. This was achieved through the transgenic knockdown of HIPM expression, highlighting the importance of this protein during $E$. amylovora infection. From an applied point of view, this is a major step forward, since new breeding strategies directed to its suppression, i.e., genome editing techniques like CRISPR/Cas9, could provide a durable solution to fire blight. Importantly, this work has also expanded our knowledge of the mechanism of infection of apple by E. amylovora as well as the plant response. HIPM directly interacts with MdOEE, a protein potentially involved in the oxidative burst necessary for infection and a possible new target for plant breeders.

\section{MATERIALS AND METHODS}

Plasmids, plant material, and transformation.

The coding region of the HIPM gene was amplified (Supplementary Table S1 lists primers), was cloned into the 
pHannibal vector, using XhoI and KpnI to insert $M d H I P M$ in sense and $B a m \mathrm{HI}$ and $\mathrm{XbaI}$ to insert it in antisense orientations, and was then subcloned in the NotI site of the binary vector pART27 (Gleave 1992). This gene-silencing plasmid was transformed into apple (cv. Galaxy) via Agrobacterium tumefaciens-mediated transformation.

In vitro plant material was cultivated with $16 \mathrm{~h}$ of light and $8 \mathrm{~h}$ of darkness at 20 to $24^{\circ} \mathrm{C}$. Plant transformation, regeneration, and selection of transgenic apple (cv. Galaxy) plants were carried out as described by Malnoy et al. (2006). Once in-vitro transgenic plants were confirmed by PCR, they were propagated and acclimated as described by Bolar et al. (1998).

\section{Growth measurements.}

For measurement of plant growth, six plants per transgenic line were grown in a glasshouse at $24^{\circ} \mathrm{C}$. For testing the effect of $\mathrm{HrpN}$ on apple shoot growth, Messenger at $0.5 \mathrm{mg} / \mathrm{ml}$ (containing $15 \mu \mathrm{g}$ of HrpN per milliliter) (Eden Bioscience Bothell) and water as a control treatment were sprayed on the plants in excess. The lengths of the shoots and of the three longest leaves per plant were measured 1 week after spraying. All data were analyzed statistically with Duncan's multiple range test according to the general linear model procedure of SAS (version 9.0; SAS Institute).

\section{Determination of fire blight resistance.}

The evaluation for fire blight resistance was performed as described by Malnoy et al. (2007). In brief, vigorously growing shoots of transgenic plants (10 to 20 shoots per line) and nontransformed control plants were inoculated by cutting the youngest expanded leaf with scissors that had been dipped in a suspension of E. amylovora (strain Ea273, $5 \times 10^{7} \mathrm{CFU} \mathrm{ml}^{-1}$ ) in two to three independent experiments. Disease severity was rated, 1 month after inoculation, as percentage of the total shoot length necrotized (length of the necrosis/total length of the shoot growth $\times 100$ ). Inoculated shoot tips became orange-brown and, eventually, dark brown, often with production of cloudy ooze droplets, which darkened with time. These symptoms proceeded basipetally on the inoculated shoot, eventually terminating at a distance based on the susceptibility of the shoot.

\section{Total RNA isolation, gene expression.}

Total RNA was extracted from leaves with Spectrum plant total RNA kit (Sigma-Aldrich). Total RNA $(2 \mu \mathrm{l})$ was treated with DNAse (Ambion) and was then reverse-transcribed with SuperScript VILO cDNA synthesis kit (Invitrogen), according to manufacturer instructions. Real-time qPCR was conducted using the BioRad CFX96 system (Bio-Rad Laboratories). iTaq universal SYBR green supermix $(6.25 \mu \mathrm{l})$ (Bio-Rad Laboratories) was used for each reaction in a total volume of $12.5 \mu \mathrm{l}$ plus $2 \mu \mathrm{l}$ of cDNA and $0.4 \mu \mathrm{M}$ of each primer. qPCR conditions were $5 \mathrm{~s}$ at $95^{\circ} \mathrm{C}$, followed by 40 cycles of $5 \mathrm{~s}$ at $95^{\circ} \mathrm{C}, 5 \mathrm{~s}$ at $58^{\circ} \mathrm{C}, 5 \mathrm{~s}$ at $60^{\circ} \mathrm{C}$, and $10 \mathrm{~s}$ at $76^{\circ} \mathrm{C}$, followed by $98^{\circ} \mathrm{C}$ for $30 \mathrm{~s}$, and an increment of $0.2^{\circ} \mathrm{C}$ per second from 65 to $95^{\circ} \mathrm{C}$ for melting curve detection. Each reaction was performed in triplicate. Apple Actin (actin2), ubiquitin (Ubi) and elongation factor $1(E F 1)$ were used as internal reference genes for normalization. The BioRad CFX manager software version 3.0 was used to analyze the relative expression level, using the normalized-expression method.

\section{Identification of putative HIPM and OEE in plant genomes and phylogenetic analysis.}

Several plant genomes present in the PLAZA 3.0 (Proost et al. 2015) were screened for HIPM (EU078328) and MdOEE (MDP0000248920) orthologous proteins. The HIPM ortholog sequences retrieved were subsequently analyzed for their evolutionary relationship and molecular phylogenetic trees (maximum likelihood model), constructed using the MEGA7 software (Kumar et al. 2016) after alignment via ClustalW (Larkin et al. 2007).

\section{Yeast two-hybrid assay.}

A yeast two-hybrid assay was set up for screening of HIPM interacting proteins in apple. The library was prepared using the Make Your Own 'Mate \& Plate' library kit (Clontech). RNA was extracted with a Plant RNA isolation mini kit (Agilent Technologies) from apple (cv. Golden Delicious) leaves inoculated or not with Erwinia amylovora Ea273. Roots and flowers at different stages of development were used to synthesize cDNA, using the SMART cDNA synthesis kit (Clontech). The cDNA libraries were cloned in the Matchmaker prey vector pGADT7. The prey constructs were integrated via in vivo recombination into the Y187 yeast strain.

The full-length HIPM gene was cloned into the pGBKT7 bait vector by PCR making use of primers with a 15-bp homology to the linear ends of pGBKT7. The bait construct was transformed in the Y2HGold yeast strain. The Matchmaker gold yeast twohybrid system (Clontech) was used for the identification of HIPM interacting proteins. Bait and prey strains were mated, and the positive interactions were selected following the manufacturer's instructions. From the colonies growing on the four drop-out medium (SD-Ade -His -Leu -Trp/X $\alpha$ Gal/AbA), the prey insert was identified by sequencing using $\mathrm{T} 7$ primer. The sequences were analyzed by alignment to a plant genomes database (National Center for Biotechnology Information BLAST) and then to the apple genome (The Rosaceae genome databasehttp://www.rosaceae.org/).

\section{Localization and BiFC assays.}

HIPM and MdOEE full-length cDNAs were cloned into $\mathrm{pENTR/D-TOPO} \mathrm{(Invitrogen)} \mathrm{and} \mathrm{were} \mathrm{transferred} \mathrm{to} \mathrm{desti-}$ nation vectors with LR-clonase reactions, into pEarleyGate104 for localization and into expression vectors pSITE-BiFCC1nec, pSITE-BiFC-C1cec, pSITE-BiFC-N1nen, and pSITEBiFC-N1cen for BiFC assays (Martin et al. 2009). Vectors were transformed into Agrobacterium tumefaciens EHA 105. Agrobacterium tumefaciens carrying the construct of interest were grown in Luria Bertani medium supplemented with appropriate antibiotics, $20 \mu \mathrm{M}$ acetosyringone, and $10 \mathrm{mM}$ MES KOH, $\mathrm{pH}$ 5.7 , at $28^{\circ} \mathrm{C}$ for $20 \mathrm{~h}$, then were resuspended in infiltration buffer (10 $\mathrm{mM} \mathrm{MgCl}_{2}, 10 \mathrm{mM}$ MES-KOH, pH 5.7) supplemented with $200 \mu \mathrm{M}$ acetosyringone at a final optical density at $600 \mathrm{~nm}$ of 1.0, and were incubated at room temperature for $4 \mathrm{~h}$. For BiFC, eight different combinations of vectors were cotransformed in $N$. benthamiana leaves as reported by Ohad et al. (2007). For localization, agrobacterium carrying the two different genes were infiltrated individually in $N$. benthamiana leaves. Following incubation for $72 \mathrm{~h}$ at $25^{\circ} \mathrm{C}, N$. benthamiana leaves were examined using a Leica DM6000 CS confocal microscope (Leica). YFP was visualized by excitation with an argon laser at $514 \mathrm{~nm}$. Leica application suite 3.7 software was used for image acquisition and processing.

\section{ACKNOWLEDGMENTS}

We gratefully acknowledge M. J. Abbot, S. A. Kuehne, and H. L Gustafson for excellent technical assistance.

\section{LITERATURE CITED}

Abbink, T. E., Peart, J. R., Mos, T. N., Baulcombe, D. C., Bol, J. F., and Linthorst, H. J. 2002. Silencing of a gene encoding a protein component of the oxygen-evolving complex of photosystem II enhances virus replication in plants. Virology 295:307-319. 
Aldwinckle, H. S., Way, R. D., Livermore, K. G., Preczewski, J. L., and Beer, S. V. 1976. Fire blight in the Geneva apple collection. Fruit Var. J. 30:42-55

Baldo, A., Norelli, J. L., Farrell, R. E., Jr., Bassett, C. L., Aldwinckle, H. S., and Malnoy, M. 2010. Identification of genes differentially expressed during interaction of resistant and susceptible apple cultivars (Malus $\times$ domestica) with Erwinia amylovora. BMC Plant Biol. 10:1.

Bocsanczy, A. M., Nissinen, R. M., Oh, C. S., and Beer, S. V. 2008. HrpN of Erwinia amylovora functions in the translocation of DspA/E into plant cells. Mol. Plant Pathol. 9:425-434.

Bogdanove, A. J., Bauer, D. W., and Beer, S. V. 1998. Erwinia amylovora secretes DspE, a pathogenicity factor and functional AvrE homolog, through the Hrp (type III secretion) pathway. J. Bacteriol. 180:2244-2247.

Bolar, J. P., Norelli, J. L., Aldwinckle, H. S., and Hanke, V. 1998. An efficient method for rooting and acclimation of micropropagated apple cultivar. HortScience 33:1251-1252.

Broggini, G. A., Wöhner, T., Fahrentrapp, J., Kost, T. D., Flachowsky, H., Peil, A., Hanke, M. V., Richter, K., Patocchi, A., and Gessler, C. 2014. Engineering fire blight resistance into the apple cultivar 'Gala' using the FB_MR5 CC-NBS-LRR resistance gene of Malus $\times$ robusta 5. Plant Biotechnol. J. 12:728-733.

Calenge, F., Drouet, D., Denancé, C., Van de Weg, W. E., Brisset, M. N., Paulin, J. P., and Durel, C. E. 2005. Identification of a major QTL together with several minor additive or epistatic QTLs for resistance to fire blight in apple in two related progenies. Theor. Appl. Genet. 111:128-135.

Durel, C. E., Denancé, C., and Brisset, M. N. 2009. Two distinct major QTL for resistance to fire blight co-localize on linkage group 12 in apple genotypes 'Evereste' and Malus floribunda clone 821. Genome 52: 139-147.

Emeriewen, O., Richter, K., Kilian, A., Zini, E., Hanke, M.-V., Malnoy, M., and Peil, A. 2014. Identification of a major quantitative trait locus for resistance to fire blight in the wild apple species Malus fusca. Mol. Breed. 34:407-419.

Emeriewen, O. F., Richter, K., Hanke, M.-V., Malnoy, M., and Peil, A. 2015. The fire blight resistance QTL of Malus fusca (Mfu10) is affected but not broken down by the highly virulent Canadian Erwinia amylovora strain E2002A. Eur. J. Plant Pathol. 141:631-635.

Gardiner, S. E., Norelli, J. L., de Silva, N., Fazio, G., Peil, A., Malnoy, M., Horner, M., Bowatte, D., Carlisle, C., Wiedow, C., Wan, Y., Bassett, C. L., Baldo, A. M., Celton, J. M., Richter, K., Aldwinckle, H. S., and Bus, V. G. 2012. Putative resistance gene markers associated with quantitative trait loci for fire blight resistance in Malus 'Robusta 5' accessions. BMC Genet. 13:25.

Gaudriault, S., Malandrin, L., Paulin, J. P., and Barny, M. A. 1997. DspA, an essential pathogenicity factor of Erwinia amylovora showing homology with AvrE of Pseudomonas syringae, is secreted via the Hrp secretion pathway in a DspB-dependent way. Mol. Microbiol. 26:1057-1069.

Gleave, A. P. 1992. A versatile binary vector system with a T-DNA organisational structure conducive to efficient integration of cloned DNA into the plant genome. Plant Mol. Biol. 20:1203-1207.

Gusberti, M., Klemm, U., Meier, M. S., Maurhofer, M., and Hunger-Glaser, I. 2015. Fire blight control: The struggle goes on. A comparison of different fire blight control methods in Switzerland with respect to biosafety, efficacy and durability. Int. J. Environ. Res. Public Health 12: 11422-11447.

Holtappels, M., Noben, J. P., and Valcke, R. 2016. Virulence of Erwinia amylovora, a prevalent apple pathogen: Outer membrane proteins and type III secreted effectors increase fitness and compromise plant defenses. Proteomics 16:2377-2390.

Jones, A. M., Thomas, V., Bennett, M. H., Mansfield, J., and Grant, M. 2006. Modifications to the Arabidopsis defense proteome occur prior to significant transcriptional change in response to inoculation with Pseudomonas syringae. Plant Physiol. 142:1603-1620.

Kamber, T., Buchmann, J. P., Pothier, J. F., Smits, T. H., Wicker, T., and Duffy, B. 2016. Fire blight disease reactome: RNA-seq transcriptional profile of apple host plant defense responses to Erwinia amylovora pathogen infection. Sci. Rep. 6:21600.

Khan, M. A., Duffy, B., Gessler, C., and Patocchi, A. 2006. QTL mapping of fire blight resistance in apple. Mol. Breed. 17:299-306.

Kost, T. D., Gessler, C., Jänsch, M., Flachowsky, H., Patocchi, A., and Broggini, G. A. 2015. Development of the first cisgenic apple with increased resistance to fire blight. PLoS One 10:e0143980.

Kumar, S., Stecher, G., and Tamura, K. 2016. MEGA7: Molecular evolutionary genetics analysis version 7.0 for bigger datasets. Mol. Biol. Evol. 33:1870-1874.

Larkin, M. A., Blackshields, G., Brown, N. P., Chenna, R., McGettigan, P. A., McWilliam, H., Valentin, F., Wallace, I. M., Wilm, A., Lopez, R.,
Thompson, J. D., Gibson, T. J., and Higgins, D. G. 2007. Clustal W and Clustal X version 2.0. Bioinformatics 23:2947-2948.

Le Roux, P. M., Khan, M. A., Broggini, G. A., Duffy, B., Gessler, C., and Patocchi, A. 2010. Mapping of quantitative trait loci for fire blight resistance in the apple cultivars 'Florina' and 'Nova Easygro'. Genome 53:710-722.

Lee, H.-A., Lee, H.-Y., Seo, E., Lee, J., Kim, S.-B., Oh, S., Choi, E., Choi, E., Lee, S. E., and Choi, D. 2017. Current understandings of plant nonhost resistance. Mol. Plant-Microbe Interact 30:5-15.

Lee, L. Y., Fang, M. J., Kuang, L. Y., and Gelvin, S. B. 2008. Vectors for multi-color bimolecular fluorescence complementation to investigate protein-protein interactions in living plant cells. Plant Methods 4:24.

Lewis, J. D., Wan, J., Ford, R., Gong, Y., Fung, P., Naha, H., Wang, P. W., Desveaux, D., and Guttman, D. S. 2012. Quantitative Interactor Screening with nextgeneration Sequencing (QIS-Seq) identifies Arabidopsis thaliana MLO2 as a target of the Pseudomonas syringae type III effector HopZ2. BMC Genomics 13:8.

Malnoy, M., Jin, Q., Borejsza-Wysocka, E. E., He, S. Y., and Aldwinckle, H. S. 2007. Overexpression of the apple MpNPR1 gene confers increased disease resistance in Malus $\times$ domestica. Mol. Plant-Microbe Interact 20: 1568-1580.

Malnoy, M., Martens, S., Norelli, J. L., Barny, M. A., Sundin, G. W., Smits, T. H., and Duffy, B. 2012. Fire blight: Applied genomic insights of the pathogen and host. Annu. Rev. Phytopathol. 50:475-494.

Malnoy, M., Reynoird, J. P., Borejsza-Wysocka, E. E., and Aldwinckle, H. S. 2006. Activation of the pathogen-inducible Gst1 promoter of potato after elicitation by Venturia inaequalis and Erwinia amylovora in transgenic apple (Malus $\times$ domestica). Transgenic Res. 15:83-93.

Martin, K., Kopperud, K., Chakrabarty, R., Banerjee, R., Brooks, R., and Goodin, M. M. 2009. Transient expression in Nicotiana benthamiana fluorescent marker lines provides enhanced definition of protein localization, movement and interactions in planta. Plant J. 59:150-162.

Nissinen, R. M., Ytterberg, A. J., Bogdanove, A. J., VAN Wijk, K. J., and Beer, S. V. 2007. Analyses of the secretomes of Erwinia amylovora and selected hrp mutants reveal novel type III secreted proteins and an effect of HrpJ on extracellular harpin levels. Mol. Plant Pathol. 8:55-67.

Nwugo, C. C., Lin, H., Duan, Y., and Civerolo, E. L. 2013. The effect of 'Candidatus Liberibacter asiaticus' infection on the proteomic profiles and nutritional status of pre-symptomatic and symptomatic grapefruit (Citrus paradisi) plants. BMC Plant Biol. 13:59.

Oh, C. S., and Beer, S. V. 2007. AtHIPM, an ortholog of the apple HrpNinteracting protein, is a negative regulator of plant growth and mediates the growth-enhancing effect of HrpN in Arabidopsis. Plant Physiol. 145: 426-436.

Ohad, N., Shichrur, K., and Yalovsky, S. 2007. The analysis of proteinprotein interactions in plants by bimolecular fluorescence complementation. Plant Physiol. 145:1090-1099.

Peil, A., Garcia-Libreros, T., Richter, K., Trognitz, F. C., Trognitz, B., Hanke, M. V., and Flachowsky, H. 2007. Strong evidence for a fire blight resistance gene of Malus robusta located on linkage group 3. Plant Breed. 126:470-475.

Perazzolli, M., Malacarne, G., Baldo, A., Righetti, L., Bailey, A., Fontana, P., Velasco, R., and Malnoy, M. 2014. Characterization of resistance gene analogues (RGAs) in apple (Malus $\times$ domestica Borkh.) and their evolutionary history of the Rosaceae family. PLoS One 9:e83844.

Pessina, S., Angeli, D., Martens, S., Visser, R. G., Bai, Y., Salamini, F., Velasco, R., Schouten, H. J., and Malnoy, M. 2016. The knock-down of the expression of MdMLO19 reduces susceptibility to powdery mildew (Podosphaera leucotricha) in apple (Malus domestica). Plant Biotechnol. J. 14:2033-2044.

Proost, S., Van Bel, M., Vaneechoutte, D., Van de Peer, Y., Inzé, D., Mueller-Roeber, B., and Vandepoele, K. 2015. PLAZA 3.0: An access point for plant comparative genomics. Nucleic Acids Res. 43 (D1): D974-D981.

Sarowar, S., Zhao, Y., Soria-Guerra, R. E., Ali, S., Zheng, D., Wang, D., and Korban, S. S. 2011. Expression profiles of differentially regulated genes during the early stages of apple flower infection with Erwinia amylovora. J. Exp. Bot. 62:4851-4861.

Sundin, G. W., Castiblanco, L. F., Yuan, X., Zeng, Q., and Yang, C. H. 2016. Bacterial disease management: Challenges, experience, innovation and future prospects. Mol. Plant Pathol. 17:1506-1518.

van Schie, C. C. N., and Takken, F. L. W. 2014. Susceptibility genes 101: How to be a good host. Annu. Rev. Phytopathol. 52:551-581.

Venisse, J. S., Barny, M. A., Paulin, J. P., and Brisset, M. N. 2003. Involvement of three pathogenicity factors of Erwinia amylovora in the oxidative stress associated with compatible interaction in pear. FEBS Lett. 537:198-202. 
Venisse, J. S., Gullner, G., and Brisset, M. N. 2001. Evidence for the involvement of an oxidative stress in the initiation of infection of pear by Erwinia amylovora. Plant Physiol. 125:2164-2172.

Venisse, J. S., Malnoy, M., Faize, M., Paulin, J. P., and Brisset, M. N. 2002. Modulation of defense responses of Malus spp. during compatible and incompatible interactions with Erwinia amylovora. Mol. Plant-Microbe Interact 15:1204-1212.

Vergne, E., de Bernonville, T. D., Dupuis, F., Sourice, S., Cournol, R., Berthelot, P., Barny, M. A., Brisset, M. N., and Chevreau, E. 2014. Membrane-targeted HrpNEa can modulate apple defense gene expression. Mol. Plant-Microbe Interact 27:125-135.

Vogt, I., Wöhner, T., Richter, K., Flachowsky, H., Sundin, G. W., Wensing, A., Savory, E. A., Geider, K., Day, B., Hanke, M. V., and Peil, A. 2013. Gene-for-gene relationship in the host-pathogen system Malus $\times$ robusta 5-Erwinia amylovora. New Phytol. 197:1262-1275.

Vrancken, K., Holtappels, M., Schoofs, H., Deckers, T., and Valcke, R. 2013. Pathogenicity and infection strategies of the fire blight pathogen Erwinia amylovora in Rosaceae: state of the art. Microbiology 159: 823-832.

Wei, Z. M., Laby, R. J., Zumoff, C. H., Bauer, D. W., He, S. Y., Collmer, A., and Beer, S. V. 1992. Harpin, elicitor of the hypersensitive response produced by the plant pathogen Erwinia amylovora. Science 257:8588.
Winslow, C. E., Broadhurst, J., Buchanan, R. E., Krumwiede, C., Rogers, L. A., and Smith, G. H. 1920. The Families and genera of the bacteria: Final report of the Committee of the Society of American Bacteriologists on characterization and classification of bacterial types. J. Bacteriol. 5: 191-229.

Yamamoto, Y., Ishikawa, Y., Nakatani, E., Yamada, M., Zhang, H., and Wydrzynski, T. 1998. Role of an extrinsic 33 kilodalton protein of photosystem II in the turnover of the reaction center-binding protein D1 during photoinhibition. Biochemistry 37:1565-1574

Zou, J., Rodriguez-Zas, S., Aldea, M., Li, M., Zhu, J., Gonzalez, D. O., Vodkin, L. O., DeLucia, E., and Clough, S. J. 2005. Expression profiling soybean response to Pseudomonas syringae reveals new defense-related genes and rapid HR-specific downregulation of photosynthesis. Mol. Plant-Microbe Interact 18:1161-1174.

\section{AUTHOR-RECOMMENDED INTERNET RESOURCES}

Expasy PredictProtein software: https://www.predictprotein.org PLAZA 3.0 software:

http://bioinformatics.psb.ugent.be/plaza/versions/plaza_v3_dicots The Rosaceae genome database: http://www.rosaceae.org/ 